\title{
CONTEMPORARY ARCHITECTURE BASED ON ALGORITHMS
}

\author{
${ }^{1}$ Patrik Márk MÁDER, ${ }^{2}$ Olivér RÁK, ${ }^{3}$ István Ervin HÁBER \\ ${ }^{1,2}$ Breuer Marcel Doctoral School, Department of Engineering Studies \\ Institute of Smart Technology and Engineering, Faculty of Engineering and Information \\ Technologies, University of Pecs, Boszorkány u. 2, 7624 Pécs, Hungary \\ e-mail: ${ }^{1}$ patrik.mader@mik.pte.hu, ${ }^{2}$ rakoliver90@gmail.com \\ ${ }^{3}$ Department of Mechanical Engineering, Institute of Smart Technology and Engineering, \\ Faculty of Engineering and Information Technologies, University of Pecs, Boszorkány u. 2 \\ 7624 Pécs, Hungary, e-mail: ihaber@mik.pte.hu
}

Received 24 January 2018; accepted 14 May 2018

\begin{abstract}
The algorithms are the part of the life which could give a solution for simple and complex problems. Most of the ways are easy, but the basics are always made by predetermined steps. The peculiarity of the sciences can be explained with these process-based principles. The following rules are the same in the architecture also. Nowadays the algorithms are more improved the fact of the expectations of the $21^{\text {st }}$ century. The creator can make a lot of rules which can support the workflow with the correct logical connections.

Since the computer aided design became available, the relationship between the architecture and information sciences getting stronger. To solve the most of the problems, it needs information technology programing techniques, logical methods and algorithms. The free geometric design, the compliance constraint with economic aspects, analysis and the optimization processes require new solutions.

The article will give an overview about the expectations of the future architects along the general knowledge and the practical examples. The study will show the development of the new professions according to the increased amount of data. Examine the competence of the contemporary architects and look for the issue of 'the architect is a programmer.'
\end{abstract}

Keywords: Visual programming, Building information modeling, Architecture, Automate, Algorithm, Computer aided design, Building industry workflow, Database management

\section{Introduction}

The design process for architects and engineers has evolved a lot since the first drawings with feather and ink. In the end of the 20th century, Computer-Aided Design (CAD) software became commonly used by designers in order to improve the quality, 
the ease of use and the speed of the representation process. As it was for all the technologies, the turn of the century involved many developments in the field of computer aided design and modeling. Many researches had been facilitated by the fast evolution of technologies and calculation/modeling capacities of personal computers [1].

The discussed phases were necessary to reach the level of the current opportunities. Charles M. Eastman was the first person who specified the doctrines of the Building Information Modeling (BIM) in 1975 [2]. The revolution of the BIM was started in the $21^{\text {st }}$ century [3]. The innovation was relevant in the fields of information producing during the planning process, data management and the communication between different disciplines. At the beginning of the usage it was enough, but the generative architecture and the economic expectations requires developments.

The new methods need to manage the changes, the recurrence and the variety of the elements in an intelligent way. The Algorithm-Aided modeling Design (AAD) and the Algorithm-Aided Building information modeling (AAB) [4] were developed to give a solution for those issues. The AAB process gives the environment for the improvement of the BIM models, which means a higher integration of the programming into the architecture and construction (Fig. 1). These methods induce the creation of new disciplines.

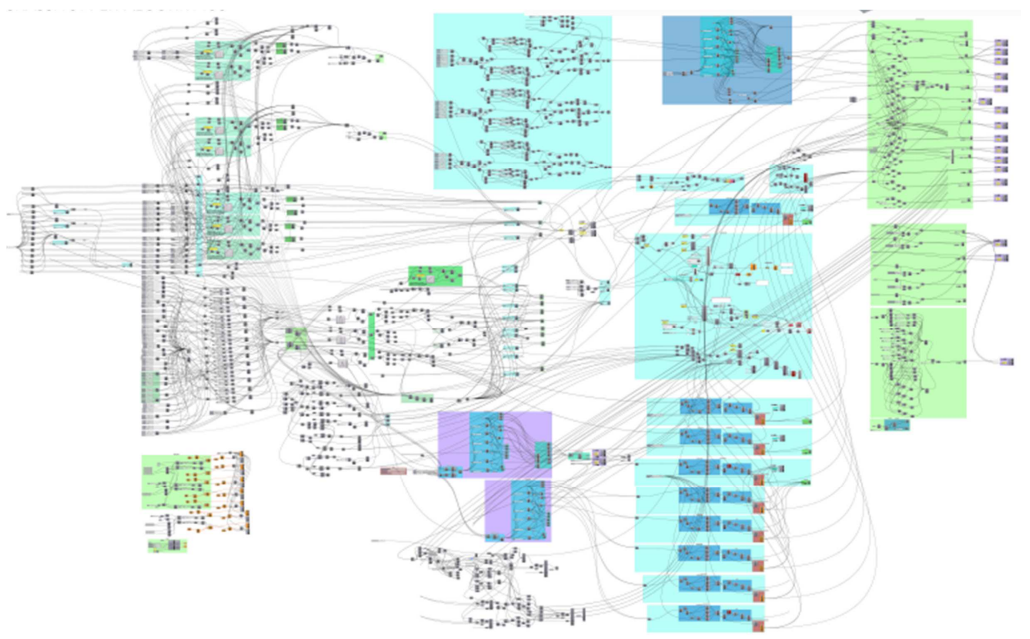

Fig. 1. General appearance of a Grasshopper algorithm-aided building information model detail

\section{Algorithms in the architecture}

\subsection{Possibilities and problems in contemporary architecture}

Architecture had a lot of definition, discipline and art classification, and separation in the past. The most commonly used definition is that: Architecture is the tool of design for buildings and environments with the help of art, technical and engineer tools. 
Nowadays the architecture is becoming more complex, the current definitions are still valid, but the complexity of these is even higher. In case of planning and construction processes the difference disciplines have their own specialties [5]. In the past the amount of the knowledge was less than today and because of this the architects has known everything about this profession. In the present days it is impossible to know, that is why the engineers cannot be the experts of the whole task.

The improvement of the Information Technology (IT) and the architecture leads to a new relationship between them, and those statements will become more acceptable. The programing processes in the architectural workflows are the best representations of the new statements, for instance the production and modification of a 3D building model become more and more prominent in case of production planning.

The article of Wortman and Tuncer [6] shows a lot of great case studies in this subject. They describe the application possibilities of the parametric planning and modeling processes and in their conclusion; they prove the successful applicability of the textual and visual programing languages in the architectural workflow.

The modern contemporary architecture starts with presence of the CAD programs. Against with the usage of the traditional architectural tools newer possibilities appeared, which caused a reformation in the methods and procedures. Nowadays the development is not slowing, moreover faster and faster innovation can be observed. It is necessary to use the potential of the changes in the building industry.

The previous statement is valid for the architectural planning also. The algorithmbased processes give advantage; nevertheless this can only be achieved by qualified experts.

The architect could have the competence of the programing languages, which are commonly used in the architecture, but this knowledge is usually less than it is needed in case of a problem solving. In an optimized way the background knowledge needs to serve the comprehending programing concepts and communicate it to the experts (Fig. 2).

\section{ARCHITECT $\neq$ PROGRAMMER}

Fig. 2. The architect is not a programmer

\section{Building information modeling}

Nowadays the building information modeling is the most developing technology and methodology of the building industry, which is currently on the highest level of the computer-aided design and construction information processing. There is lots of definition, which are always changing because of the fast technology developing and the expanding areas of use. The first accepted definition claims, that every section, floorplan, isometric and perspective views are generated from the model directly [2]. If the model is changing then all of the plans and the views are changing automatically, 
and any type of model-based quantity analysis, cost estimation and building material quantity calculation can be generated from the model [2]. In addition, this could be a base for time scheduling and building material ordering [2].

In contrast the right definition of current situation is that: a BIM is a shared knowledge resource for information about a building forming a reliable basis for decisions during its life cycle, [3] (Fig. 3). BIM is a digital representation of physical and functional characteristics of a building [3]. A basic premise of BIM is collaboration by different stakeholders at different phases of the life cycle of a building to insert, extract, update or modify information in the BIM to support and reflect the roles of that stakeholder [3].

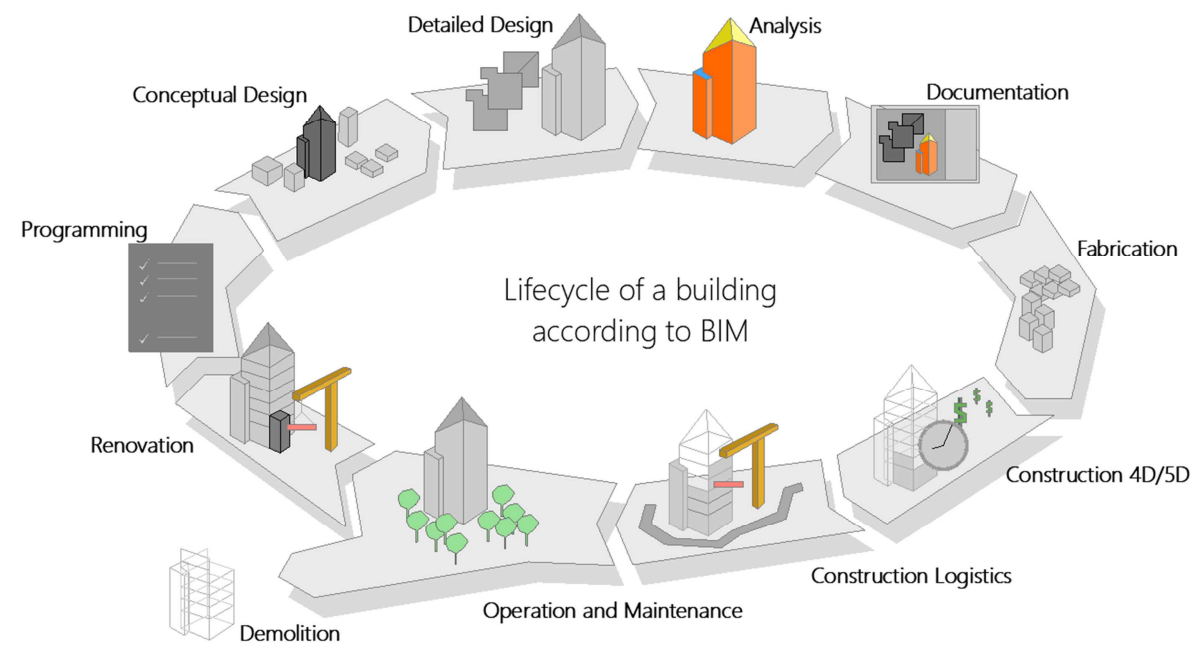

Fig. 3. Lifecycle of a building according to BIM

The BIM is trying to give a technical support in every part of the building industry from the conceptual planning, trough the construction support to the building operating, demolition and maintenance phases [7].

Initially, the virtual models on the different Level Of Development (LOD) and model elements provided the required data, but graphic design and derivative information became inadequate [8]. It is essential for the documentation according to the regulations; nevertheless the 2D meta-data management of the model elements (which is independent of the graphical design) will be more important in case of building information modeling because of the workflow complexity.

The following grouping shows the most common fields which are using BIM in the building industry.

The BIM can be adaptable for: [9]

- $\quad$ spatial planning and coordination;

- the plan documentation according to the phases, and to display the correct drawing details; 
- the production of different BIM models with various information content (for instance: energy, time scheduling, quantity, investment information model).

All of the definitions need to mean the same for every stakeholder of the project. Accurately built methodologies and guidelines are indispensable to solve this issue, these are the standards. In abroad the technology is controlled by the governments long ago, but there is few years lag in Hungary. Probably the solution will come from the Hungarian Standardization Corporate and the Lechner Knowledge Center because they began to define the Hungarian standards [10].

The European Union has a guideline, which contains that every member state need to have their own BIM guidelines and standards within a few years. In order to meet the requirements by the Hungarian professional audience and country, it is inevitable to create the system in Hungarian language adapted to the Hungarian environment [10].

\section{Education}

It is necessary to have an adequate quality in the architecture and contemporary architecture education to have engineers with the appropriate expertise. The education is more complicated like earlier, because architecture IT lectures are needed also. This is indispensable to teach the building information modeling, parametric structural design and the object-oriented and visual programing languages in the universities.

To reach this goal the educational institutions have to change their own strategies, and have to make practice orientated education possible. To study the earlier discussed new disciplines like BIM experts or architecture programing must to have changes in the education.

Many great programing training is available, but these are not contains the architectural studies, and provide a wide range of IT knowledge that is generally not necessary for building industry programmers. As the paragraph 2.1 revealed, the architect should not be a programmer, but the new knowledge of the new disciplines could be learned during a specialization process.

\subsection{Visual programing in the architecture}

As it was considered in paragraph 2.1 , the contemporary and the future architecture competence needs to contain the possibilities of the architectural programing knowledge. Many programing language make it possible for the engineers and architectures. Guilherme Ferreira [11] and Bruna Ferreira [12] wrote a great and impeccable article in this topic, therefore this paragraph will present the most popular method's general ideas and the summary of the experiences.

The most popular and used methods are the object-oriented and visual programing processes, which were developed in the 1980-1990 years [13]. Most of the companies, whose are producing architecture programs, implemented the software background and collaboration possibilities into their products. Every kind of object-oriented programing method, which allows the user to manipulate the model without text code-works only with the help of graphical commands, is called visual programing. The specialties are in the graphical symbols, which are connecting to each other with lines, curves or arrows [14]. One of the earlier examples was developed by Alan Kay in 1968, which is the 
GraIL (Graphical Input Language) programing surface. This interface was able to identify the freehanded algorithms [15]. The method was developed since then. New opportunities have been created by the new CAD software (e.g. Rhinoceros) and the BIM compatible programs (e.g. Autodesk Revit (hereinafter called: Revit), Graphisoft Archicad (hereinafter called: Achicad)). The latter is a good solution, because in the past the biggest issue was the interoperability between the programs, which was solved. If it is necessary to change models between different software the most efficient way is to use the Industry Foundation Classes (IFC) [16], [17] standard and file format. Nevertheless it is not perfect at this time, but the IFC can give a good solution if the geometry and graphical design software, algorithm-based tool and the program used during the design processes are the same. As it was mentioned before, the biggest software companies recognized the needs, which allow using algorithm-based tools, the Grasshopper and Dynamo in collaboration with Archicad and Revit software. The peculiarity of the Grasshopper is the possibility to use together with all of these two platforms.

In a consideration about the areas of the usage, this can be stated, that there is countless different way to use but the application is limited by a few main area. Most of the articles write about primary usage of visual programming in architecture, automated geometric transform [18], analysis [19], [20], simulations [21], [22] (Fig. 4) and optimization [22] (Fig. 5) workflows. It is evidential because of the higher expectations in case of ergonomic design and energy design of a building as well as the efficiency of the planning process induces an economical contest.

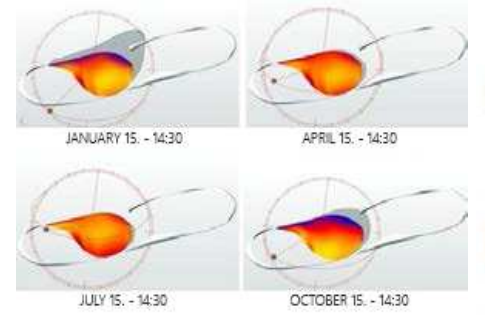

Fig. 4. Energetic simulation example from Autodesk Ecotect
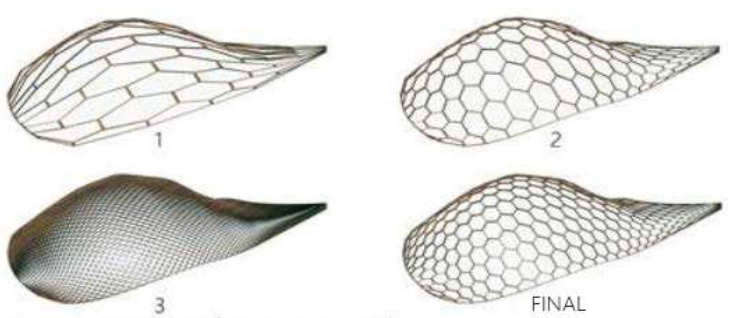

Fig. 5. Loadbearing skeleton optimization example from Grasshopper

The use of algorithm-based planning with the correct input parameter and data while respecting sustainable design principles, can save many time and resource compared to the manual processes [23] (according to Mohammad Rahmani Asl, Saied Zarrinmehr , Michael Bergin, Wei Yan article). The authors made some energy simulation in case of sunlight with their own developed BPOpt (Optimo) tool, which defined the yearly energy consumption costs. The possibilities of the simple conceptual modifications made easy to analyze many option.

Lot of good study can be found in the textural programing language topic also. One of those is Allianz Arena in München, which was made Autodesk AutoCad Rosetta tool by Caetani and Leitao [24]. 
As the examples show most of the interest are in the geometric transformation and the saving with analysis. Nevertheless the documentation, data management and controlling has a big potential also.

\section{Conclusion}

The algorithm-based planning, parametric design and visual programing can be an efficient process in the construction workflows, but it depends on the acceptance, training and appropriate attitude of engineers.

The combination of the algorithms and BIM make possible to use it in special cases, which follows to make 5 main groups:

- Support for the conceptual planning process;

- Support for the higher level planning process;

- Documentation support;

- Construction support;

- Supervision support.

Some of the subgroups are ready to use, but the most of them needs a lot of development. Unfortunately the everyday usage of these techniques is still waiting for itself. The solution for this issue could be the specialization, new principles developing, and education of the experts, as it was considered in paragraph 2.1.

\section{References}

[1] Denis F. Tool for augmented parametric building information modeling for transformable buildings, Master's Thesis, Brussel Faculty of Engineering, 2014

[2] Eastman C. M. The use of computers instead of drawings in building design, AIA Journal, Vol. 63, No. 3, 1975, pp. 46-50.

[3] Azhar S., Khalfan M., Maqsood T. Building Information Modeling (BIM): Now and beyond, Construction Economics and Building, Vol. 12, No 4, 2012, pp. 15-28.

[4] Humppi H. Algorithm-aided building information modeling, Master's Thesis, Tampere University of Technology, 2015.

[5] Liao A. The 21st-century skill set for architect, 2015.06.02, http://www.architect magazine.com/practice/the-21st-century-skill-set-for-architects_o, (last visited 21 October 2017).

[6] Wortmann T., Tuncer B. Differentiating parametric design: Digital workflows in contemporary architecture and construction, Design Studies, Vol. 52, 2017, pp. 173-197.

[7] Abanda F. H., Kamsu-Foguem B., Tah J. H. M. BIM - New rules of measurement ontology for construction cost estimation, Engineering Science and Technology, an International Journal, Vol. 20, No. 2, 2017, pp. 443-459.

[8] Level of development specification, Part I, BIMForum, 2017.

[9] Zagorácz M. The possibilities of BIM, (in Hungarian) http://lechnerkozpont.hu/ data/sites/default/files/pic/article/jovot-tanulni-jottek/prezentacio/ zagoracz-mark-a-bimlehetosegei.pdf, (last visited 15 October 2017). 
[10] Lechner Knowledge Center: Unified communication in architecture (in Hungarian) http://lechnerkozpont.hu/cikk/egyseges-kommunikacio-az-epiteszetben, (last visited 23 October 2017).

[11] Ferreira G. An enhanced programming environment for generative design, Master's Thesis, Instituto Superior Técnico, Universidade de Lisboa, 2016.

[12] Ferreira B. F. B. Generative design for building information modeling, Master's Thesis, Instituto Superior Técnico, Universidade de Lisboa, 2015.

[13] Éles V. The development of programing languages, and improvement, The properties of the procedure and object oriented languages, definitions, Development of the graphical environment and event-oriented programming, (in Hungarian) http://www. inczedy.hu/ viktoria/prog/2_ora/progr_nyelvek.pdf, (last visited 15 October 2017).

[14] Nagy Á. Visual Programing, Final examination, (in Hungarian) BSc Thesis, Moholy-Nagy University of Art and Design, Budapest, 2007.

[15] Denis F. Tool for augmented parametric building information modeling for transformable buildings, Master's Thesis, Vrije Universiteit Brussel, 2014.

[16] buildingSMART-IFC 4, Industry foundation classes - IFC4 Official Release, http://www. buildingsmart-tech.org/ifc/IFC4/Add2/html/, (last visited 20 October 2017).

[17] Wijayakumar M., Jayasena H. S. Automation of BIM quantity take-off to suit QS's requirements, The Second World Construction Symposium Socio-Economic Sustainability in Construction, Colombo, Sri Lanka, 14-15 June 2013, pp. 70-80.

[18] Zarzycki A. Parametric BIM as a generative design tool, ACSA 2012, Boston, MA, 1-4 March 2012, pp. 752-762.

[19] Sárközi R., Iványi P., Széll A. B. Classification of parametric design techniques - Types of surface patterns, Pollack Periodica, Vol. 12, No. 2, 2017, pp. 173-180.

[20] Baranyai B., Bachmann B., Kistelegdi I. Simulation-supported design of a Hungarian national sports center, Pollack Periodica, Vol. 11, No. 1, 2016, pp. 113-127.

[21] Oti A. H., Tizani W., Abanda F. H., Jaly-Zada A., Tah J. H. M. Structural sustainability appraisal in BIM, Automation in Construction, Vol. 69, 2016, pp. 44-56.

[22] Mirtschin J. Engaging generative BIM workflows, Rhino News, 28 November 2011.

[23] Asl M. R., Zarrinmehr S., Bergin M., Yan W. BPOpt: A framework for BIM-based performance optimization, Energy and Buildings, Vol. 108, 2015, pp. 401-412,

[24] Caetano I., Leitao A. Using processing with architectural 3D modeling, $34^{\text {th }}$ International Conference on Education and Research in Computer Aided Architectural Design in Europe, Oulu, Finland, 24-26 August 2016, pp. 405-412. 